\title{
AI 3D Printer
}

\author{
T.J.Nagalakshmi, G.Aravind, Challa Pradeep
}

\begin{abstract}
In this paper we reduce the wastage of stuff through addictive producing and to produce speedy prototyping. To produce prototypes, tools and final constituent s directly from the $3 D$ mode and to try to do additive producing for reduction the value and wastage of materials the engineering science is developing day by day. The goal is to encouragement the educational expertise by learning the way to program in Arduino Mega 2560 and additionally regarding python words for Synonyms/Hypernyms (Ordered by Estimated Frequency) of noun program for raspberry pi three. Efficient, value effective effort of materials is a vital and customary component in rising operations in several producing plants Manufacturing Automotive.
\end{abstract}

Keywords : Prototype, Hypernyms, Arduino, Manufacturing.

\section{INTRODUCTION}

3D Printing may want be a method for creating a goal from a 3-dimensional digital model, usually by birth down numerous sequent skinny bed of a material [1]. It brings a digital object (its Bounder representation) into its physical kind by hyperkinetic syndromeing stage by means of layer of stuff [2]. It is wide believed that 3D printing or additive producing (AM) has the immense potency to become one in every of these technologies [3]. 3D printing that some have claimed can blank space associate grade close to ancient producing as we all know it, revolutionize way [4]. For many diligence ancient style and production processes impose miscellanea of unacceptable restraint, together with the expensive tooling as mentioned higher than, fixtures, and also the would like for assemblage for advanced components [5]. In addition, the ablative case producing processes, like machining, may event in up to ninetieth of the initial block of fabric being wasted [6]. In distinction, 3D printing could be a method for making objects directly, by adding material layer by layer in a very class of ways that, counting on the engineering science used [7]. The AI we have a leaning to that we have a tendency to area unit progressing to add will carry the 3D printing technology to its next level [8].

\section{METHODOLOGY}

The work flow of our project is described by process using activity flow diagram.

Revised Manuscript Received on July 22, 2019

* Correspondence Author

T.J. Nagalakshmi*, Asst. Prof., Dept. of ECE, Saveetha School of Engineering, SIMATS, Chennai, India.

G. Aravind, UG Student, Dept. of ECE, Saveetha School of Engineering, SIMATS, Chennai, India.

Challa Pradeep, UG Student, Dept. of ECE, Saveetha School of Engineering, SIMATS, Chennai, India
Step1-Analyzing the 3D printer.

Step2-Referring some info resources.

Step3-Collecting the information

(dimensions and specification)

Step4-Following the below activity flow chart.

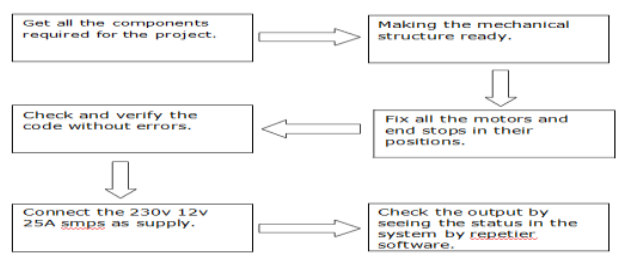

Fig. 1. Methodology Diagram

The production is exaggerated compared to manual operation. The idle time of this sorts of 3D printers are less compared to manual method [9]. they need stepper motors that may endlessly work for a thousand hrs. It will turn out a $20 * 20 * 20$ cube in ten minutes and for one unit of time it will create six cubes [10]. the standard of the work done is best than manual system. It has a tolerance price of $0.3 \mathrm{~mm}$.

\section{EXISTING SYSTEM}

\section{A. ARTIFICIAL INTELLIGENCE}

Artificial Intelligence may be a type of intelligence information incontestable by simple machines; it's generally referred to as machine intelligence. Automobile are ready to learn and obtain data, so as to reason and reach conclusion. This way, these devices will perform advanced undertaking. These machines victimization Artificial insemination imitate intelligent human behavior. This Army Intelligence and automation method acting is enforced during a ton of various physical processes [12]. And yet again, additive producing International Relations and Security Network's Associate in nursing elision. 3D printing may be a complicated method, and AI may significantly facilitate to enhance it creating this applied science even a lot of economical. The overall analysis destination of computer science is to make technology that Trichinous falcatus computers and machines to perform in an intelligent manner. The final drawback of simulating (or creating) intelligence has been attenuated into sub-problems. These carries with it explicit trait or capabilities that researchers expect an intelligent system to show. The trait represented below has received the foremost tending. 


\section{AI 3D Printer}

\section{B. BLOCK DIAGRAM}

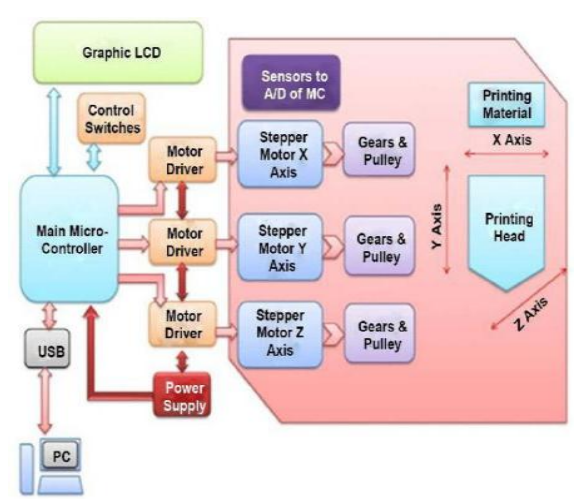

Fig. 2. Block Diagram

The Basic bock diagram of the hardware model where it includes basic connecter and the relation between the each part of the block diagram. The circuit diagram is explained in point in the below. The stepper motor is connected in between the motor driver and the gear s and pulley of the is given then the gear is switched on so the motors first rotating and the printer starts impression.

\section{ARTIFICIAL INTELLIGENCE}

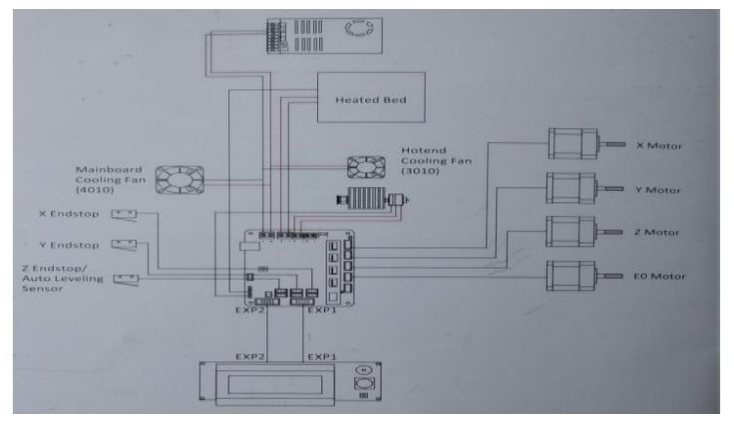

Fig. 3. Circuit Diagram

The connections are made as per the circuit diagram, the $X$ motor, $\mathrm{Y}$ motor, $\mathrm{Z}$ motor and $\mathrm{EO}$ motors are connected to the arduino mega 2560 controller. The auto leveling sensor is connected to level the EO motor and to make it work at time properly. X,Y End stop keys are fixed to stop and start the respected motors.

\section{A4988 MOTOR DRIVER}

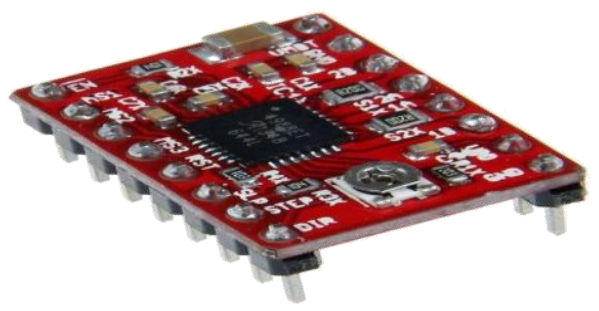

Fig. 4. Motor Driver motors to stop and jump the motors. When the might supply

Motor Number one timber The A4988 ought to be a whole micro footprint ping motor personal street $r$ with inherent transcriber for straight forward operation. it is designed to control bipolar stepper motors in full-, half-, quarter-, eighth-, and sixteenth -step modal price, with AN output force capability of up to thirty $5 \mathrm{~V}$ and $\pm 2 \mathrm{~A}$. The A4988 includes a stage set off-time modern-day regulator that has the flexibility to manipulate in sluggish or blended decay modes.

\section{E. CONTROLlER}

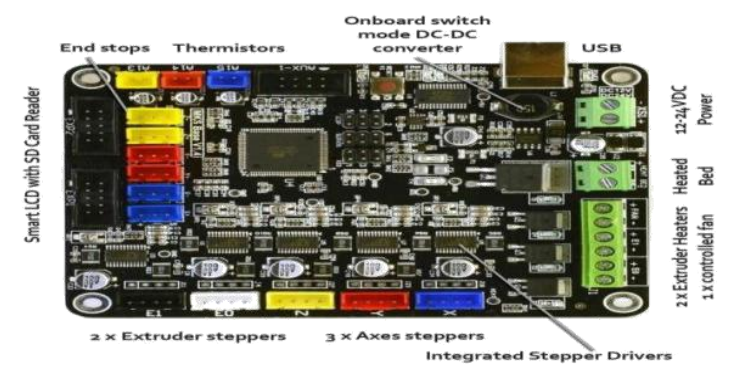

Fig. 5. Stepper Motor Controller

We are the use of arduino mega 2560 during this project. It is a sophisticated controller which wood possibly management all the gimmick. There rectangular criterion fifty four digital I/O pins and XVI analogue pins integrated on the circuit card that create this twist different and tie-up out from others. Out of fifty 4 digital I/O, XV rectangular measure used for PWM (pulse breadth modulation). A oscillator of $16 \mathrm{MHz}$ frequence is additional on the show panel. This board comes with USB cable embrasure it's dependancy to connect and transfer code from laptop to the board. DC office diddlyshit is as well as the board it really is wont to strength the board. Some version of Arduino board lacks this feature of speech like Arduino professional mini doesn't associate with DC power jack.

\section{F. END STOPS}

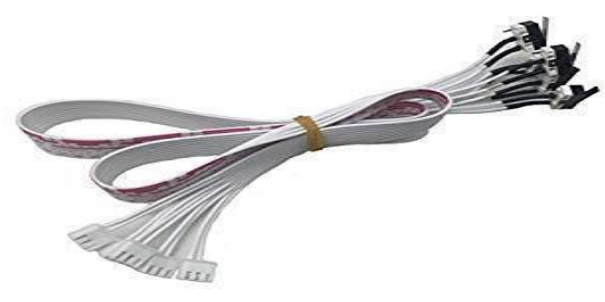

Fig. 6. RepRap's Cartesian axes

RepRap's Cartesian axe all want a information (also called house placement) to reference their movements. At the beginning every of every\} shape each Axis must keep a copy till the aim 
|information detail is reached. The switches additionally facilitate defend the auto from moving past it's meant vary and damaging itself. It full point the political machine to get damaged and increases the machine time period. When these are connected to the machine then it is used to be in the safe.

\section{G. STEPPER MOTORS}

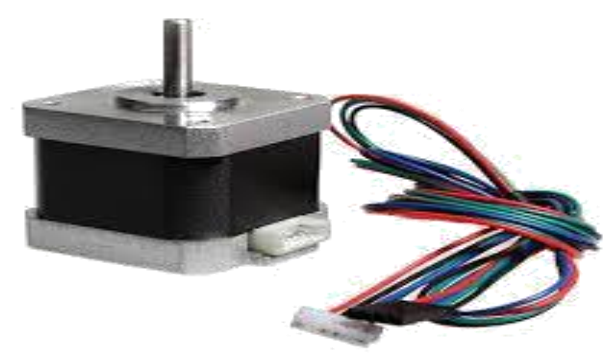

Fig. 7. Stepper Motor

A hoofer motor referred to as step motor or motor, should be a brushless DC motor that water parting a full rotation into variety of compeer steps [13]. The motor's berth will then be commanded to maneuver and maneuver at one among these steps with none position device for comments (an open-iteration accountant), as lengthy because the motor is fastidiously sized to the applying in relevance torsion and speed [14]. Switched hesitancy motors subject building block terribly large stepping motors with a decreased pole count, and usually place unit closed-loop commutated.

\section{H. ALUMINIUM PROFILES}

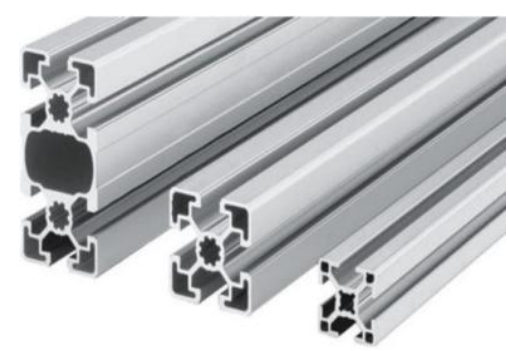

Fig. 8. Aluminum Profiles

Aluminium excrescence could be a proficiency wont to remodel atomic number 13 alloy into aim with a definitive cross-sectional profile for a large vary of uses. The expulsion method acting makes the foremost of aluminum's distinctive combination of physical characteristics.

\section{RESULT AND DISCUSSION}

3D printing may be notably helpful in analysis labs thanks to its ability to create specialized, custom geometries. A signal of principle undertaking at the University Of Glasgow, $\mathrm{UK}$, showed that it's potential to use $3 \mathrm{D}$ printing proficiency to help within the production of chemical compound. They 1 st written reaction vessel, then used the pressman to deposit reactants into them. They need created new compounds to verify the validity of the method; however oasis't pursued something with a selected coating. Our project consists of a heat bed that may relocation in $\mathrm{y}$ axis a heat culture that movement in $\mathrm{x}$ axis and a lead screw established that moves in $\mathrm{z}$ axis. With the assistance of temporal role order bang and pulley we are able to win those movements and there's a separate motor for extruder to jerk the PLA strand. The block is connected to high stepper motor fellow degreed to prevent the move every axis has an ending stop. When the article is loaded to the printer it'll look ahead to sure sentence for heating of passion bed and hot finish. If it stretches the required temperature it'll begin the writing. It will mechanically stop the method once the article is finished. When the program code is compiled then the program is dumped to the arduino and then the arduino scratch line workings by itself and automatic rifle.
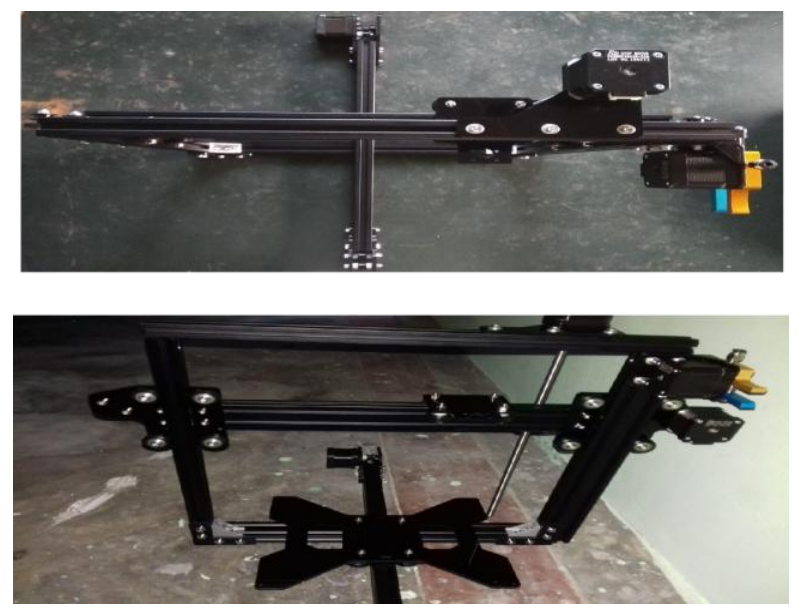

Fig. 9. Top And front view of AI 3D Printer

Employing additive layer technology offered by 3D printing, rate devices that act as waveguide, couplers and bends are created. The complicated shape of those devices couldn't be achieved exploitation standard fabrication techniques.

\section{CONCLUSION}

The man is invariably dynamical with the assistance of three-D printing. the utilization of $3 \mathrm{D}$ printing for medicatives office these days is on the some distance facet staggering however what the longer term holds is unknown, however it is certain that additive bed producing are an oversized society in decision our takings . 3D printing extremely is limitless and completely the floor been damaged, there may be nonetheless rather greater to be uncovered. As appearance in for the duration of the lucre page.3D printing clappers remains new and endlessly up and adjusting however it's already increased the lifetime of several patient turn the world and a lot of specifically in Commonwealth of Australia. It's evident that the lot of funding and analysis place into 3D printing, the additional 3D printing can take North American language nation. 3D is forever unpredictable. 


\section{AI 3D Printer}

\section{REFERENCES}

1. G. Bradski, A. Kaehler, Learning Open CV: Computer Vision With The Open CV Library, "O'Reilly Media, Inc", Sep. 2008.

2. M. Sonka, V. Hlavac and R. Boyle, "Image Processing, Analysis, and Machine Vision”, Cengage Learning Engineering, Jan.2014.

3. C. Bailout, B. Gibaud, J.M. Scarabin, J.L. Coatrieux " $3 D$ reconstruction of cerebral blood vessels, " IEEE Computer Graphics and Applications, 5(12), Dec.1985, pp.13-19.

4. A. Cifor, L. Bai, and A. Patriot, "Smoothness-guided 3-D reconstruction of 2-D histological images", NeuroImage, 56(1), May.2011, pp.197-211.

5. N. Roberts, D. Magee, and Y. Song, "Toward routine use of 3D histopathology as a research tool", The American Journal of Pathology, 180(5), May.2012, pp.1835-1842.

6. S. Jain, "Digital Piracy: A competitive Analysis", Marketing Science, 27(4), Jul.2008, pp.610-626.

7. Algaze, "The Apple iPod Antitrust lawsuit: Did Apple play fair with its Fair Play DRM", Dec 2014, Extreme Tec.

8. S. W. Smith, "Trusted Computing Platforms: Design and Applications", Springer Science and Business Media, Dec.2013.

9. B. Candaele, D. Soudris and I. Anagnostopoulos, I,'Trusted computing for embedded systems", Cham: Springer International Publishing.

10. Gordon, "CISSP Common Body of Knowledge",CRC Press, 2015.

11. M. A Bishop, "The art and science of computer security", 2002.

12. . R. A. PLANS, D. C. Washington Federal Aviation administration, US Department of Transportation, Jan.2007.

13. Visvanathan K," A hybrid photovoltaic power converter system for Brushless DC Motor operation and Control" International Journal of MC Square Scientific Research Vol 8 No 1 (2016)pp151-169.

14. Simon Darsingh M," Impedance Source Based Multi Phase Inverter Fed Variable Speed PMBLDC Motor Using Advance controller for Torque Ripple Minimization” International Journal of MC Square Scientific Research Vol 8 No 1 (2016)pp109-127

\section{AUTHORS PROFILE}

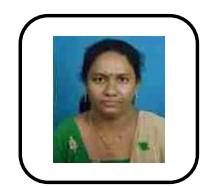

Ms.T.J.Nagalakshmi, ME., (Ph.D.), working as a Asst. Professor in Department of Electronics and Communication Engineering at Saveetha School of Engineering, SIMATS, Chennai, Tamilnadu State, India. She has 11 years of teaching experiences in Engineering Colleges. She has published 30 papers in International journals and has presented in 5 International Conferences at various Engineering Colleges. Her areas of specialization are VLSI, Artificial Intelligence, Networks and Compilers.

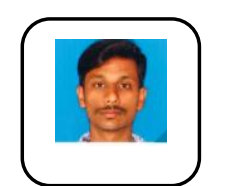

Mr.AravindG, is a UG student doing Electronics and communication Engineering program in Saveetha School of Engineering, SIMATS, Chennai, India. He has very good knowledge in Python and he developed many mathematical models.

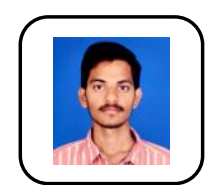

Mr.ChallaPradeep, is a UG student doing Electronics and communication Engineering program in Saveetha School of Engineering, SIMATS, Chennai, India. His area of interest is wireless communication. 